\section{B A Institute of \\ YK Business Administration \\ 六下 \\ Karachi \\ Leadership and Ideas for Tomorrow}

Business Review

Volume 12 Issue 1 January-June 2017

$1-1-2017$

\title{
Does volatility scaling improve the performance of momentum strategies in the Pakistan Stock Exchange?
}

\author{
Mohsin Sadaqat \\ Department of Finance and Investment, National University of Science and Technology (NUST), \\ Islamabad, Pakistan \\ Hilal Anwar Butt \\ Department of Economics and Finance, Institute of Business Administration
}

Follow this and additional works at: https://ir.iba.edu.pk/businessreview

Part of the Finance and Financial Management Commons

\section{(c) (1)}

This work is licensed under a Creative Commons Attribution 4.0 International License.

\section{Recommended Citation}

Sadaqat, M., \& Butt, H. A. (2017). Does volatility scaling improve the performance of momentum strategies in the Pakistan Stock Exchange?. Business Review, 12(1), 1-19. Retrieved from https://doi.org/ 10.54784/1990-6587.1046

This article is brought to you by iRepository for open access under the Creative Commons Attribution 4.0 License and is available at https://ir.iba.edu.pk/businessreview/vol12/iss1/1. For more information, please contact irepository@iba.edu.pk. 


\title{
Does volatility scaling improve the performance of momentum strategies in the Pakistan Stock Exchange?
}

\author{
Mohsin Sadaqat · Hilal Anwar Butt
}

\begin{abstract}
Momentum profits are low among stocks listed on the Pakistan Stock Exchange. We explore whether this can be improved by exploiting the predicted negative relationship between returns and volatility of momentum strategies. This relationship suggests that momentum returns increase/decrease with decrease/increase in the volatility/variance of momentum returns during the previous six months. We find that scaled momentum strategies outperform the traditional strategy in terms of higher raw returns, risk-adjusted returns and Sharpe ratios. To show the superiority of scaled momentum strategies, we bootstrap the sample 100,000 times and generate the lognormal distribution of holding-period returns for all momentum strategies. We find that the probability of negative returns for the scaled strategy declines from $39 \%$ to $8 \%$ in comparison to the traditional momentum strategy.
\end{abstract}

Keywords Momentum - Volatility scaling - Risk adjusted returns · Sharpe ratio $\cdot$ Holding period returns $\cdot$ Long-term investment · Bootstrapping.

\section{Introduction}

Momentum is one of the most documented anomalies, achieved by going long (short) in the stocks that have performed well (poor) in the recent past. Jegadeesh and Titman (1993) documented this anomaly for the first time in the US market over a medium term investment horizon of 3 to 12 months. Since

Mohsin Sadaqat

Department of Finance and Investment, National University of Science and Technology (NUST), Islamabad, Pakistan

E-mail: mohsin.sadaqat@nbs.nust.edu.pk

Hilal Anwar Butt

Department of Economics and Finance, Institute of Business Administration (IBA), Karachi, Pakistan

(C)Sadaqat, M. and Butt, A. H. 2017 
then, literature has persistently examined momentum returns over time in most of the markets around the world (Asness et al 2013). ${ }^{1}$ These predictable momentum profits calculated by using history of returns, which is publicly available information, negate even the weak form of market efficiency. Surprisingly, the magnitude of momentum profits as documented by Rouwenhorst (1999); Chui et al (2010) are quite low for emerging markets as compared to the most developed market of the US. ${ }^{2}$ The potential reason could be the highly volatile nature of emerging markets as documented in (Kusnadi and Hameed 2002).

Barroso and Santa-Clara (2015); Daniel and Moskowitz (2016) link the existence of momentum profitability with the premium that investors may demand for the partially predictable momentum crashes. For example, in the US market, a simple momentum strategy (t-12 to t-2)(Barroso and Santa-Clara 2015; Daniel and Moskowitz 2016). ${ }^{3}$ crashed to an extent of $-91.59 \%$ during the great depression of 1932 and to $-73.42 \%$ in the 2009 global financial crisis. ${ }^{4}$ Although, such market crashes occur in extreme adverse market conditions, their incidence wipes away the profits earned in decades and it takes ages to recover even the initial invested amount. Are these crashes avoidable on ex ante basis? This interesting question is first addressed by Grundy and Martin (2001) by making an important observation that momentum strategy has significant negative market exposure, which in down market states when the market astoundingly rebounds, results in momentum crashes. ${ }^{5}$ However, this finding as per Daniel and Moskowitz (2016) is ex-post and therefore cannot be implemented on exante basis.

Barroso and Santa-Clara (2015); Daniel and Moskowitz (2016) propose that the previous 126 days' volatility/variance related information of momentum strategy can be used as a scaling factor for the traditional momentum strategies to avoid momentum crashes. This volatility/variance related information is publicly available and thus presents a greater challenge to weak form of market efficiency. Nevertheless, this finding paves way for an interesting aspect of research to analyze the implication of this result as an investment strategy for more volatile markets.

The evidence on the performance of scaled strategies for the US market is mainly reported in (Barroso and Santa-Clara 2015; Daniel and Moskowitz 2016). ${ }^{6}$ Previous literature indicates that emerging markets have lower momentum returns Rouwenhorst (1999) and they are volatile (Kusnadi and Hameed 2002). These two characteristics of emerging markets motivate us to incorpo-

\footnotetext{
1 Momentum phenomenon is also present across different asset classes.

2 For example, a simple momentum strategy for the US market as per Fama and French website yields about $12 \%$ annual returns for the span of $1927-2016$, whereas in PSX these returns are only $5.65 \%$ for $1993-2016$.

3 This momentum strategy is similar to that reported on French website and used extensively in the literature for details.

4 Daniel and Moskowitz (2016) identified 15 such crashes in Table 1 of their paper.

5 Daniel and Moskowitz (2016) define down market state as, when the previous 24 months cumulative market returns are negative. Furthermore, in this study we use down market state and bear market state interchangeably.

6 For robustness, they tested such strategies on other markets however; most of these markets are developed.
} 
rate volatility related information in momentum strategies and then compare the performance of such strategies with the traditional one. To fulfil this purpose we select the Pakistan Stock Market (PSX) as an emerging market due to its highly volatile nature. Moreover, the results reported so far on momentum profitability in the PSX are inconsistent across samples. We also test the performance of scaled momentum strategies across different sub samples to show that the performance of scaled strategies is not sample specific. Furthermore, in Pakistan previous studies on PSX ignore the long-term perspective of momentum profitability. We bridge this gap and compare the performance of momentum strategies in the long-term.

Consistent with the results of previous studies on Pakistan, we find that traditional momentum strategy yields statistically insignificant and economically low returns. Furthermore, the negative relationship between momentum returns and lagged volatility show the importance of volatility related information on ex ante basis. Using this information (inverse of volatility/variance as a scaling factor), we construct scaled momentum strategies which perform better than traditional momentum strategies. That is, by keeping the target volatility of both scaled and traditional momentum strategy same, the raw-returns almost double in the case of scaled momentum strategies. ${ }^{7}$ In addition to this, Asset pricing models such as Capital Asset Pricing Model (CAPM) of Sharpe (1964), Three-Factor-Model (FF3) of Fama and French (1993) and Four-Factor-Model (CF4) of Carhart (1997) produce larger alpha for scaled momentum strategies. However, CFF4 model explains the risk of scaled momentum strategies adequately and alpha are insignificant. Overall, scaled momentum strategies outperform traditional strategies, yet they do not constitute that big a pricing challenge to at least the CFF4 model, as is the case for the US market.

Further, we find that scaled momentum strategies also outperform traditional momentum strategy in all sub samples in terms of Sharpe ratios and risk adjusted returns. Moreover, drawing log normal distribution from simulated holding period returns of momentum strategies using the bootstrapping method, it is evident that scaled strategies perform better in the long-term as these have lower probability of negative returns.

The paper is organized as follows: section 2 discusses the previous research on momentum in the Pakistani market, section 3 provides the rationale behind volatility/variance as a scaling factor, section 4 describes the data used in the study, section 5 outlines the methodology and section 6 presents the results and discussion. In the last section, we conclude the study.

\section{Prior research on momentum in PSX}

There are very few papers available in which the momentum phenomenon has been studied in the PSX. Interestingly, most of these papers have documented contrasting results. For example, Habib-Ur-Rahman and Mohsin (2012) use 16

\footnotetext{
7 This is very much a recommended procedure for comparing the performance of different strategies on the basis of the same risk, both Barroso and Santa-Clara (2015); Daniel and Moskowitz (2016) have implied this target volatility within the context of their study.
}

Business Review: (2017) 12(1):1-19 
different momentum strategies during the period from 1999 until 2007 and report a weak evidence of momentum in the PSX. Shah and Shah (2015) identify a strong momentum effect in the PSX even after controlling for small firm bias. However, their sample is from 2004 to 2014, which is quite different to that of (Habib-Ur-Rahman and Mohsin 2012). This means that the results differ drastically because of a significant sample selection bias in momentum profits.

Tauseef and Nishat (2016) conduct a comprehensive study from 2001 to 2015 on similar momentum strategies and split the sample into two sub samples i.e. 2001-2007 and 2009-2015. They find that momentum exists for the overall sample but momentum returns are not statistically significant. Furthermore, they report a stronger effect of momentum in the first sub sample (2001-2007). Surprisingly, these results contradict the findings of Habib-Ur-Rahman and Mohsin (2012) study in which they report weak momentum effect in the PSX. Another study conducted by Khan et al (2016) reports negative momentum returns in the PSX. Nevertheless, all these studies use traditional momentum strategies.

As reported in Daniel and Moskowitz (2016), volatility plays an important role in predicting momentum returns and using this information they modify the simple momentum strategies into volatility/variance scaled momentum strategies. No study in the PSX has used such volatility/variance related information to construct momentum strategies. Therefore, in this study we bridge this gap and use volatility/variance related information to test the performance of scaled momentum strategies in the PSX. Furthermore, the sample size used in the previous studies is very small. We use a larger sample to investigate the performance of momentum strategies. Further, we have also tested the performance of scaled momentum strategies in previously reported sub-samples to make a comparison and analyzed the performance of these strategies in the long-run as investments.

\section{Motivation and rationale behind volatility scaling}

Grundy and Martin (2001) document that momentum has time varying market risk and significant negative market beta. This is because the short side of the momentum strategy, the loser portfolio has positive market beta and the long side of the strategy, the winner portfolio has lower market beta. In down market states, when the market contemporaneously re-surges the losers are highly profitable and winners incur losses. This results in momentum crashes. These market betas on loser and winner portfolio cannot be adjusted on ex-ante basis to avoid huge losses on momentum strategy. However, Barroso and SantaClara (2015) show that the quintiles constructed based on previous 126 days (6-months) volatility of momentum strategy have a negative relationship with momentum profits for the next month. ${ }^{8}$

This finding alludes that lagged momentum volatility can be used to manage momentum risk by investing more in momentum strategy when volatility is

\footnotetext{
8 Barroso and Santa-Clara (2015) have showed these results in figure 3 of their paper.
} 
Does volatility scaling improve the performance...

Table 1: Lagged volatility

\begin{tabular}{lll}
\hline \multirow{2}{*}{ Portfolios } & \multicolumn{2}{c}{ VOL } \\
\cline { 2 - 3 } & $\beta_{0}$ & $\beta_{1}$ \\
\hline $\mathrm{W}$ & 0.014 & 0.372 \\
& $(1.16)$ & $(0.66)$ \\
$\mathrm{L}$ & -0.006 & 1.191 \\
& $(-0.40)$ & $(1.86)$ \\
MOM & 0.020 & -0.820 \\
& $(2.15)$ & $(-1.94)$ \\
\hline
\end{tabular}

This table shows the effect of lagged volatility on winners (W), Losers (L) and Momentum (MOM) portfolios. We use regression of the following form to check this effect. $r_{i t}=\beta_{i 0}+\beta_{i 1} V_{o l} l_{t-1}+\varepsilon_{i t}$ Where, $r_{i t}$ represents the returns on $\mathrm{W}, \mathrm{L}$ or MOM portfolio, $V_{o l-1}$ is the lagged 126 days realized volatility estimated by using Barroso and Santa-Clara (2016) procedure, $\varepsilon_{i t}$ is the residual term and are the coefficients of the regression model. This regression is estimated using the simple Ordinary Least Squares (OLS) method. T-statistics are given in parenthesis. The regression is estimated using monthly data and time spam is from September 1994 to December 2016.

low and investing less when volatility is higher. ${ }^{9}$ Further, Daniel and Moskowitz (2016) also demonstrate that momentum returns are the decreasing function of lagged market volatility in down market states. They provide intuitive interpretation of this relationship that the pay-off of the loser portfolio is akin to a call option on the market portfolio in down market states, when the market rebounds. As the market volatility is higher in such panic states, which is an underlying asset in this case, therefore the price of this call option increases as returns on the market increase. Since, momentum strategy is short in the loser portfolio, Daniel and Moskowitz (2016) suggest that the payoff of momentum strategy resembles the payoff of a written (short) call option on the market portfolio and thus incurs huge losses. Simply putting it, in down market states when the market rebounds, the loser portfolio earns higher contemporaneous returns compared to the winner portfolio and as a result, momentum collapses under such adverse market conditions.

To get a clear picture of lagged volatility and momentum relationship in the PSX, we run a simple Ordinary Least Squares (OLS) regression of the following form:

$$
r_{i t}=\beta_{i 0}+\beta_{i 1} V_{o l-1}+\varepsilon_{i t}
$$

where, $r_{i t}$ are returns on Winners $(\mathrm{W})$, Losers (L) or Momentum (MOM) portfolio and $\mathrm{Vol}_{t-1}$ is the lagged volatility of 126 days (six months). If the sign of the coefficient for momentum portfolio turns out to be negative, it implies that momentum returns are the decreasing function of lagged volatility. We present the results in table 1 . As expected and is seen for the US market, we find that momentum returns are negatively related to lagged volatility and this relationship is economically and statistically significant. This negative relationship between volatility and momentum returns motivates us to use volatility related information in the construction of scaled momentum portfolios.

\footnotetext{
9 This is exactly what, the inverse of pervious 126-days volatility till the last date of the preceding month to the construction of momentum strategy does.
}

Business Review: (2017) 12(1):1-19 


\section{Data}

We obtain all the data (both at daily and monthly frequency) from DataStream (DS). To alleviate the survivorship bias, the sample contains both the listed and de-listed (active/dead) companies from the PSX. ${ }^{10}$ We use an extended period of 22 years starting from September 1994 until December 2016. Reuters (2013) report that accounting and financial data is more reliable from 1985 onwards, therefore we obtain data from 1987 for the PSX. However, due to fewer number of firms and insufficient data points, we start our analysis from 1994 onwards. $^{11}$ This comprehensive data set reflects both the periods of strong and weak market performance and is free of sample selection bias. ${ }^{12}$ The data obtained from DS is not free from errors as pointed out by (Ince and Porter 2006). To make the data set reliable and compatible with international studies, we apply both the static and dynamic screens.

\subsection{Static screens}

We apply the static screens (independent of time and applied to all stocks) in which we retain only those stocks that fulfil the following criteria:

- Stocks which are equity by type i.e. drop all non-equity securities such as mutual funds, warrants, debt securities, unit trusts, preferred stocks etc.

- Firms listed and located inside Pakistan i.e. domestic firms.

- Stocks must be quoted in local currency i.e. Pakistani Rupee.

- Stocks with primary quotations to overcome the issue of cross listings/duplicate.

- Cases in which firms that issue multiple equities, we retain stocks with biggest market capitalization and liquidity i.e. major security.

- Stocks listed on the major stock exchange i.e. Pakistan Stock Exchange.

- Drop stocks with the industry codes: 73, 76, 77, 88, 89, 109, 110, 121, 124, $125,136,137,145,148,149,154$ and 159 . These codes refer to investment vehicles, real estate, exchange traded funds etc. For further details see: (Griffin et al 2010).

After applying the above filters, we still find many stocks which are classified as common equity however they are not of common equity type as their names contain suspicious words. A list of such suspicious words are reported in (Ince and Porter 2006; Griffin et al 2010). Therefore, to make our sample error free we applied the screens provided by Griffin et al (2010).

\footnotetext{
10 The number of companies listed on stock exchange are dynamic i.e. increase/decrease in listed companies over time.

11 Chui et al (2010) study the momentum strategies around the world. They also used data from 1993 onwards for Pakistan. We use data from 1993 however, our analysis starts from September 1994 because 11 months are used to construct momentum portfolio and 6 months are used to calculate the volatility/variance measures for scaling.

12 Previous studies on Pakistani market mostly use data from 2000 and onwards which may lead to small sample bias.
} 


\subsection{Dynamic screens}

Dynamic Screens (time series filters) are applied to stocks that pass the static screening criteria. Ince and Porter (2006) indicate that unadjusted returns may affect the portfolio returns in general and momentum strategy returns in particular. For instance, DS records the last available data point for a dead or de-listed stock, which results in zero returns data points. This biases the calculations of portfolio returns when overall market is bearish as these zero returns may outperform the market and overstate portfolio returns. To overcome these issues, we have applied the following filters as described by (Ince and Porter 2006; Griffin et al 2010; Schmidt et al 2016).

- Remove all zero returns for any firm from the bottom of the series to first non-zero returns.

- Any return greater than 800

- Similarly, if two consecutive time period returns are greater than $300 \%$ i.e. $R_{t}$ or $R_{(t-1)}>300 \%$.

- Erase two cumulative returns if value is less than $50 \%\left(1+R_{t}\right) *\left(1+R_{(t-1)}\right)-$ $1<50 \%$.

- We exclude non-trading days from the analysis. Non-trading days are those days on which more than $90 \%$ stocks have zero returns.

\subsection{Investment universe}

Following the screening criteria described in the previous sub-sections, the investable universe contains 473 stocks. However, the number of stocks varies over time as depicted in figure 1. Without applying the filters above, the total listed number of stocks are 724 in 1994 and reduced to 579 in 2016. ${ }^{13}$ After adjusting for the screens, the investment universe comprises of 106 stocks in 1994 and increases to 212 stocks in 2016. Due to the illiquid nature of the PSX, the number of firms are low at the beginning of the sample. However, the number of stocks increases with an improvement in liquidity constraints.

\section{Methodology}

\subsection{Momentum strategies}

To compare the performance of momentum strategies in the PSX, three momentum strategies are constructed. The first strategy is the conventional momentum strategy, the second is the volatility scaled momentum strategy, while the third strategy is the variance scaled momentum strategy. The detailed construction methodology is described in the subsequent section.

\footnotetext{
13 These figures are exclusive of non-equity stocks. We take these figures from World Bank database and various issues of economic surveys of Pakistan. In Data-Stream list, the total number of stocks are 976. However, this list includes all types of instruments i.e. equity, preference stocks, futures, debt etc. For simplicity, we only report stocks that are equity by nature in figure 1.
}

Business Review: (2017) 12(1):1-19 


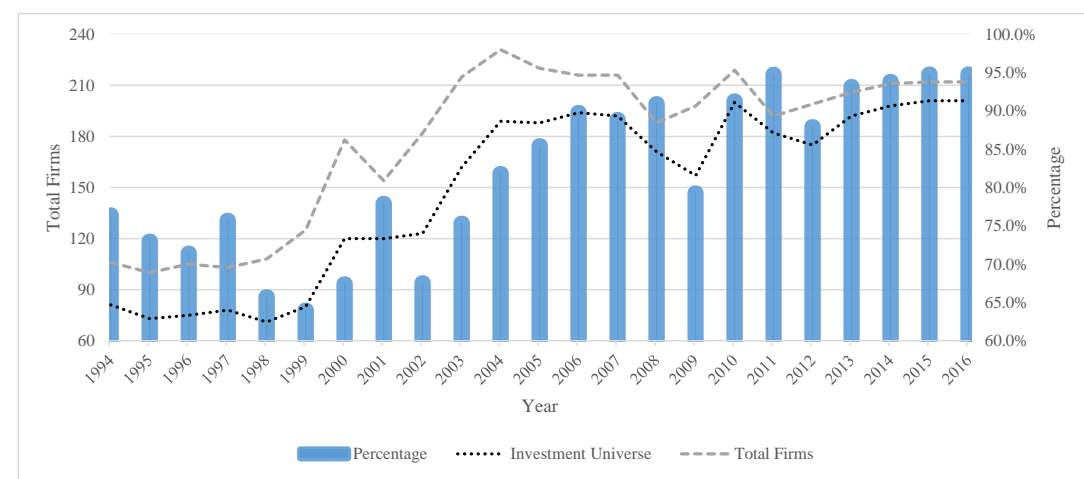

Fig. 1: Investment universe

\subsubsection{Traditional momentum strategy}

In this study, we use the average of previous 11-month returns ( $t-2$ to $t-12$ ) to construct the momentum strategy. Returns data available for less than eight monthly returns during the 11-month period are assumed to be missing and not included in portfolio construction. We calculate the periodic breakpoints using 11-months returns and group stocks into five portfolios. The first portfolio consists of stocks that have the lowest average returns, the loser (L) portfolio and the fifth portfolio comprises of stocks that have the highest average returns during the previous 11-months, the winner (W) portfolio. We then put the next month returns $(t+1)$ of each stock in the respective portfolio and calculate the cross sectional average at each time interval. We skip month t returns to account for the reversal effect and market microstructure related issues. Lastly, we get the momentum portfolio (MOM) by going long in the winner portfolio and shortening the loser portfolio.

\subsubsection{Scaled momentum strategies}

We use two different versions of scaled momentum strategies reported in (Barroso and Santa-Clara 2015; Daniel and Moskowitz 2016). Following Barroso and Santa-Clara (2015), we construct Constant Volatility Momentum (MOMCV) strategy by simply scaling the traditional momentum strategy's monthly returns by the inverse of lagged 126-days (6-months) momentum volatility. The lagged 126-days momentum volatility is computed by using equation (2) below:

$$
V O L_{t}=\sqrt{\frac{\sum_{t=1}^{126}\left(M O M_{t}-\overline{M O M}\right)}{126}}
$$

For Variance Scaled Momentum (MOMVS) strategy, we follow Daniel and Moskowitz (2016) procedure, we scale the traditional momentum returns by the inverse of previous 126-days momentum variance. We use equation (3) to calculate momentum variance.

$$
V A R_{t}=\frac{\sum_{t=1}^{126}\left(M O M_{t}-\overline{M O M}\right)}{126}
$$


In order to compare the performance of these three strategies, we equalize the standard deviation of scaled strategies to that of the traditional momentum strategy. The logic is that, if volatility/variance is not helpful in predicting returns then the risk-return framework will not hold true as the volatility/variance increases (Moreira and Muir 2016). The returns series of the two scaled momentum strategies are given in equation (4) below:

$$
M O M_{\text {Scaledt }}=\left(\frac{1}{V_{t-1}} * M O M_{t}\right) * C
$$

where $M O M_{\text {Scaledt }}$ is the return series of volatility/variance scaled strategies, $V_{t-1}$ is the lagged 126-days volatility/variance of momentum strategy, $M O M_{t}$ is the original returns series of traditional momentum strategy and $C$ is the constant, which is used to equalize the volatility/variance of scaled strategies.

Figure 2 and 3 show the weights of Constant Volatility and Variance Scaled momentum strategy over time. These weights are interpreted as the amount invested in loser and winner portfolios. It is quite evident that when the market is bearish (down market state), the weights are significantly decreased. For example during 2008-09, the weights are at their lowest due to the domestic stock market crisis and from 2009 until 2016 the weights are increasing as the market gets stable.

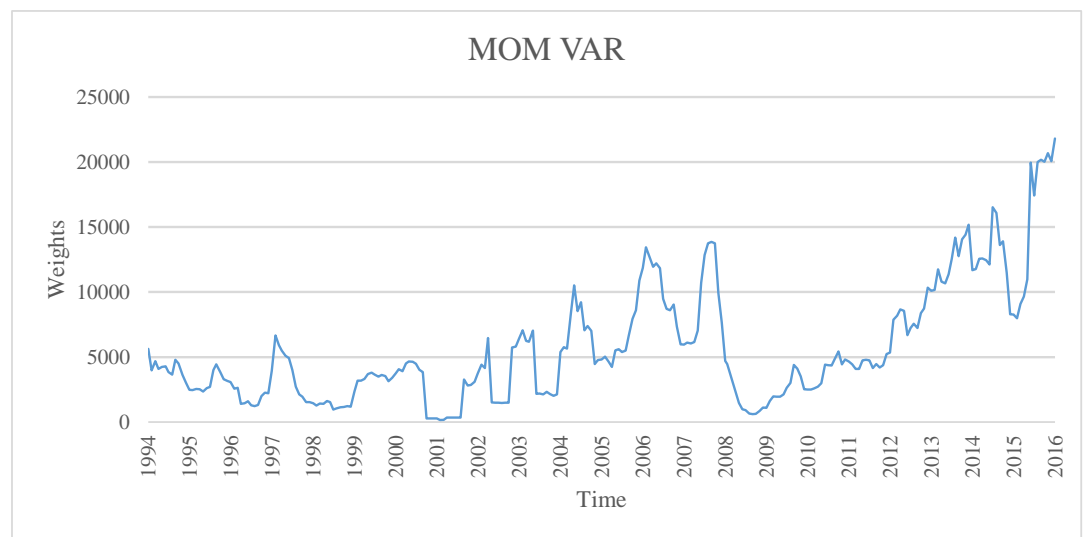

Fig. 2: Constant volatility momentum weights

\subsection{Risk based framework}

In addition to simple descriptive analysis, we use different versions of asset pricing models to rationalize the excess returns of various momentum strategies in a risk-based framework. The specifications of the models are given below:

$$
M O M_{i t}=\alpha_{i}+\beta_{C A P M i}\left(R M_{t}-R F_{t}\right)+\varepsilon_{t}
$$

Business Review: (2017) 12(1):1-19 
M. Sadaqat, H. Butt

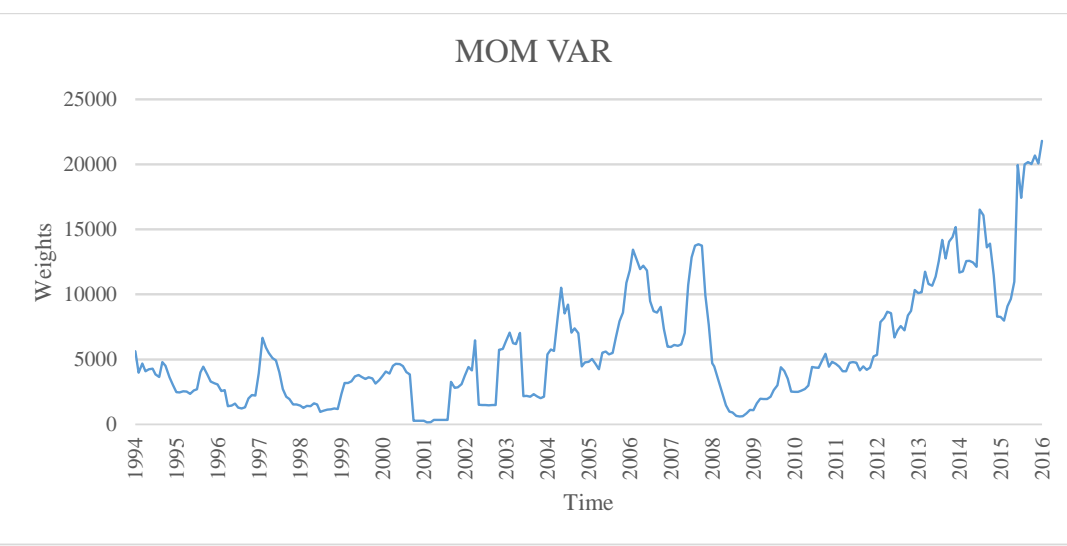

Fig. 3: Variance scaled momentum weights

$$
\begin{gathered}
M O M_{i t}=\alpha_{i}+\beta_{C A P M i}\left(R M_{t}-R F_{t}\right)+\beta_{S M B_{i}} S M B_{t}+\beta_{H M L_{i}} H M L_{t}+\varepsilon_{t} \\
M O M_{i t}=\alpha_{i}+\beta_{C A P M i}\left(R M_{t}-R F_{t}\right)+\beta_{S M B_{i}} S M B_{t}+\beta_{H M L i} H M L_{t} \\
+\beta_{W M L i} W M L_{t}+\varepsilon_{t}
\end{gathered}
$$

where MOM are the returns series of all momentum portfolio (scaled and unscaled); $R M-R F$ are the market returns in excess of 6 -months risk free rate; $S M B$ is the size premium on small minus big stocks; $H M L$ is the value premium on high minus low book-to-market stocks; $W M L$ is the premium on winner minus loser stocks. WML and MOM are two distinct portfolios. MOM is the difference between the average returns of stocks in the extreme quintile whereas $W M L$ is the difference between the average returns of top $30 \%$ and bottom $30 \%$ of stocks. $W M L$ represents the market wide systematic risk factor (mimicking portfolio).

The first model is the Capital Asset Pricing Model (CAPM) proposed by Sharpe (1964), in which there is only one single systematic factor i.e. the market factor. The second model is the Fama and French (1993) three-factor model (FF3), which is an extended version of CAPM. Two additional factors are added in the FF3 model as systematic factors i.e. Size (returns on small caps minus returns on big caps) and Value (returns on high book to market stocks minus returns on low book to market stocks). The last model is the extension of FF3 model in which another factor i.e. WML (returns on winner stocks minus returns on loser stocks) is included. We construct all the right-hand side variables by following the methodology of (Fama and French 1993; Carhart 1997).

Here the purpose is to compare the excess returns (risk adjusted) in terms of Jensen (1968) alpha of scaled momentum strategies with the risk adjusted returns of traditional momentum strategies. If the Jensen alpha of scaled strategies is economically higher than that of traditional momentum strategy then it asserts that scaled strategies are superior. 


\subsection{Long term performance comparison using bootstrapping}

To test the performance in the long-term, we simulate the log normal distribution of 22 years of holding period returns 100,000 times for each momentum strategy, using the bootstrapping method (sampling with replacement). This procedure assumes that each holding period return has an equal probability of occurrence. Instead of using simple average returns, we use holding period returns (continuously compounded returns). Running 100,000 simulations on randomly selected returns from September, 1994 until December, 2016 (22 years), we generate the frequency distribution of cumulative returns and calculate the likelihood of negative returns for each momentum strategy. We hypothesize that if lagged volatility/variance is helpful in improving the performance of scaled strategies then such strategies are less risky compared to traditional momentum strategy.

\section{Analysis of results}

\subsection{Performance comparison of momentum strategies}

Figure 4 depicts the cumulative returns of each momentum strategy achieved by an investor who invests one Pakistani Rupee from September 1994 until December $2016 .{ }^{14}$ The figure indicates that all momentum strategies produce positive holding period returns. However, in the earlier part of the sample, until 2002, almost all strategies have negative cumulative returns. This may be because the PSX was more illiquid at that time and was infrequently traded. Afterwards some structural changes were introduced in the market like, Corporate Governance Act of 2002, which helped in mustering the investors' confidence. After 2002 , the performance of scaled strategies improved significantly.

Overall, an investor in traditional momentum strategy gained only Rs. 1.46 after almost 22 years of investment whereas, with volatility/variance scaled momentum strategies this wealth increased to Rs. 4.69 and Rs. 6.32 respectively. Although these numbers are higher in comparison to traditional momentum strategy, overall, all various forms of momentum strategies under-perform in comparison to the market portfolio, which earns $25.03 \%$ cumulative returns on an annual basis for the whole sample. ${ }^{15}$ This is because in addition to lower average arithmetic returns, the higher time series fluctuations in momentum returns decrease the geometric mean of these strategies.

\subsection{Descriptive analysis}

Table 2 shows the descriptive analysis for each strategy. In panel A, the traditional momentum strategy has produced only $5.65 \%$ returns on an annual

\footnotetext{
14 We strictly assume that there is no withdrawal of either the principal or gains from such investment until at the end of the final period.

15 The results of cumulative returns for market portfolio are available upon request.
}

Business Review: (2017) 12(1):1-19 
M. Sadaqat, H. Butt

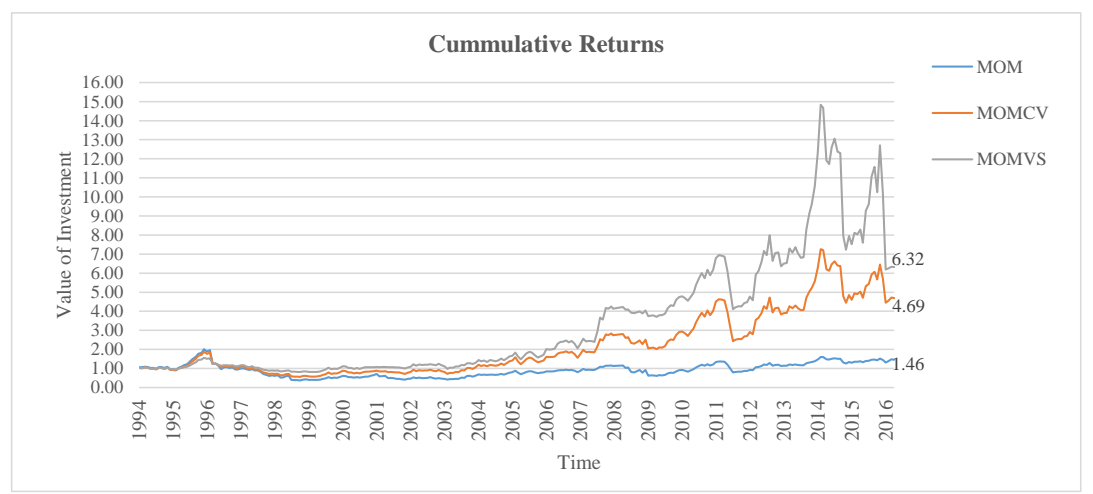

Fig. 4: Performance of momentum strategies

basis. Unlike the US market the loser portfolio has quite higher returns, which are $19.12 \%$ on an annual basis. The winner portfolio has higher average annualized return of $24.76 \%$, but the overall momentum strategy only generates $5.65 \%$ returns on an annual basis. Further these momentum returns are not statistically significant as depicted in column 3 of Panel A. Resultantly, the Sharpe ratio for the momentum strategy is only 0.21 , which is lower than 0.62 of the market portfolio. Lastly, the momentum returns are negatively skewed, indicating large losses, which are particularly disliked by risk averse investors.

In Panel B and C, we report the results of scaled momentum strategies. The returns of the scaled strategies are almost double compared to traditional momentum strategy. For Constant Volatility strategy, the momentum returns are $10.75 \%$ per annum and for Variance Scaled strategy, returns are $12.13 \%$ per annum. These returns for both the scaled strategies are statistically significant. Furthermore, there is an improvement in the Sharpe ratios of scaled strategies and the skewness is also reduced, which shows that the magnitude of negative returns is smaller than the traditional momentum strategy.

\subsection{Sub-sample analysis}

Analysis in the previous section is for the full sample starting from September 1993 until December 2016. In this section, we divide the full sample in five sub samples. Here the objective is twofold. First, we compare the results of traditional momentum strategy in each sub-sample with the previous studies. Secondly, to test for robustness we compare the performance of scaled momentum strategies in each sample with traditional momentum strategy. The results are presented in table 3. The first sub sample is from September 1994 to December 1999 which is the period when PSX was highly illiquid. During this time span, all the momentum strategies have highly negative returns. However, scaled momentum strategies perform relatively well in comparison to traditional momentum strategies during that period.

In the second sub-sample, which starts from January 2001 until 2015 Tauseef and Nishat (2016), the momentum returns turned positive (10.95\% pa) and in- 
Does volatility scaling improve the performance...

Table 2: Summary statistics of momentum strategies

\begin{tabular}{|c|c|c|c|c|c|}
\hline & $\mathrm{AvG}$ & $\mathrm{SD}$ & T-Stats & SR & SK \\
\hline \multicolumn{6}{|c|}{ Panel A: Traditional momentum strategy } \\
\hline $\mathrm{W}$ & 24.758 & 35.613 & 3.279 & 0.695 & -0.165 \\
\hline $\mathrm{L}$ & 19.107 & 40.788 & 2.21 & 0.468 & 0.739 \\
\hline MOM & 5.652 & 26.962 & 0.989 & 0.21 & -1.246 \\
\hline \multicolumn{6}{|c|}{ Panel B: Constant volatility momentum strategy } \\
\hline $\mathrm{W}$ & 28.735 & 41.538 & 3.257 & 0.692 & -0.392 \\
\hline L & 17.987 & 42.694 & 1.984 & 0.421 & 0.045 \\
\hline MOM & 10.748 & 26.962 & 1.877 & 0.399 & -0.538 \\
\hline \multicolumn{6}{|c|}{ Panel C: Variance scaled momentum strategy } \\
\hline $\mathrm{W}$ & 29.378 & 44.184 & 3.131 & 0.665 & -0.19 \\
\hline $\mathrm{L}$ & 17.248 & 45.62 & 1.78 & 0.378 & 0.588 \\
\hline MOM & 12.131 & 26.962 & 2.118 & 0.45 & -0.484 \\
\hline \multicolumn{6}{|c|}{$\begin{array}{l}\text { This table presents the summary statistics of Winners (W), } \\
\text { Losers (L) and Momentum (MOM) portfolios. Panel A } \\
\text { presents the summary statistics for traditional momentum } \\
\text { strategies while Panel B and C depict the summary statis- } \\
\text { tics for Volatility and Variance scaled momentum strategies. } \\
\text { AvG denotes the annualized average returns; SD is the annu- } \\
\text { alized standard Deviation; T-statistics tests the significance } \\
\text { of average returns; SR is the annualized Sharpe ratio and SK } \\
\text { presents the skewness of the particular portfolio. All the cal- } \\
\text { culations start from September } 1994 \text { until December } 2016 \text {. }\end{array}$} \\
\hline
\end{tabular}

creased by almost 50\%. Similarly, the Sharpe ratio also increased for scaled momentum strategies. Furthermore, Tauseef and Nishat (2016) split their sample into two sub-samples (i.e. 2001-2007 and 2009-2015) and their results show that momentum strategies are more profitable in the first sample. Using the same sub-samples, results are consistent with their study. We find that traditional momentum returns are higher in the first sub sample as compared to the second sub-sample. Nevertheless, regardless of the samples, scaled momentum strategies outperform traditional momentum strategies in all sub-samples in terms of average returns and Sharpe ratios. This show that results of this study are not confined to just one sample but are consistent across all sub samples in which scaled momentum strategies outperform traditional momentum strategies.

Moreover, we also use the sample period of (Shah and Shah 2015). Again, the results show consistency. Overall, traditional momentum returns are $12.71 \%$ per annum during 2004 to 2014 . Even in this sub sample, scaled momentum strategies have higher average returns and superior Sharpe ratios. In addition to this, in all sub samples scaled strategies have relatively small skewness compared to traditional momentum strategies making scaled strategies less risky. To sum up, volatility scaling constitutes a better market timing strategy for traditional momentum strategy, as it increases average returns and Sharpe ratios and decreases negative skewness. 
M. Sadaqat, H. Butt

Table 3: Summary statistics of sub samples

\begin{tabular}{|c|c|c|c|c|c|c|c|c|c|}
\hline & \multicolumn{3}{|c|}{ Panel A: MOMT } & \multicolumn{3}{|c|}{ Panel B: MOMCV } & \multicolumn{3}{|c|}{ Panel C: MOMVS } \\
\hline & $\mathrm{W}$ & $\mathrm{L}$ & MOM & $\mathrm{W}$ & $\mathrm{L}$ & MOM & $\mathrm{W}$ & $\mathrm{L}$ & MOM \\
\hline & \multicolumn{9}{|c|}{ 1994-1999 } \\
\hline $\mathrm{AvG}$ & -9.42 & 2.41 & -11.84 & -13.08 & -6.43 & -6.65 & -11.68 & -9.28 & -2.41 \\
\hline $\mathrm{SD}$ & 38.09 & 50.21 & 32.08 & 30.96 & 39 & 25.36 & 19.63 & 23.31 & 15.68 \\
\hline SR & -0.25 & 0.05 & -0.37 & -0.42 & -0.16 & -0.26 & -0.6 & -0.4 & -0.15 \\
\hline \multirow[t]{2}{*}{ SK } & 0.737 & 1.117 & -1.597 & 0.662 & 0.906 & -1.343 & 0.553 & 0.726 & -1.117 \\
\hline & \multicolumn{9}{|c|}{$2000-2016$} \\
\hline $\mathrm{AvG}$ & 35.72 & 24.77 & 10.95 & 41.98 & 25.72 & 16.26 & 42.39 & 25.65 & 16.74 \\
\hline SD & 34.29 & 37.25 & 24.97 & 43.67 & 43.56 & 27.26 & 48.89 & 50.4 & 29.53 \\
\hline SR & 1.04 & 0.66 & 0.44 & 0.96 & 0.59 & 0.6 & 0.87 & 0.51 & 0.57 \\
\hline \multirow[t]{2}{*}{ SK } & -0.492 & 0.525 & -0.886 & -0.644 & -0.176 & -0.372 & -0.387 & 0.439 & -0.531 \\
\hline & \multicolumn{9}{|c|}{ 2004-2016 } \\
\hline$A v G$ & 31.84 & 19.13 & 12.71 & 43.13 & 24.64 & 18.49 & 47.66 & 27.95 & 19.71 \\
\hline SD & 31.57 & 34.4 & 24.82 & 44.27 & 46.53 & 28.89 & 52.42 & 56.01 & 32.53 \\
\hline SR & 1.01 & 0.56 & 0.51 & 0.97 & 0.53 & 0.64 & 0.91 & 0.5 & 0.61 \\
\hline \multirow[t]{2}{*}{ SK } & -0.812 & -0.084 & -0.989 & -0.701 & -0.188 & -0.454 & -0.418 & 0.389 & -0.577 \\
\hline & \multicolumn{9}{|c|}{$2000-2007$} \\
\hline$A v G$ & 48.55 & 35.13 & 13.4 & 50.12 & 32.67 & 17.45 & 42.27 & 26.5 & 15.69 \\
\hline SD & 36.26 & 36.8 & 23.88 & 39.94 & 34.11 & 23.31 & 36.84 & 31.4 & 20.07 \\
\hline SR & 1.34 & 0.95 & 0.56 & 1.25 & 0.96 & 0.75 & 1.15 & 0.85 & 0.78 \\
\hline \multirow[t]{2}{*}{ SK } & -0.062 & 1.269 & -0.235 & -0.364 & 0.074 & 0.05 & -0.257 & 0.086 & 0.098 \\
\hline & \multicolumn{9}{|c|}{$2009-2016$} \\
\hline $\mathrm{AvG}$ & 36.67 & 29.83 & 6.84 & 52.01 & 40.72 & 11.29 & 60.91 & 49.03 & 11.88 \\
\hline SD & 26.5 & 33.24 & 26.79 & 39.35 & 44.44 & 30.57 & 50.84 & 57.77 & 35.58 \\
\hline SR & 1.38 & 0.9 & 0.26 & 1.32 & 0.92 & 0.37 & 1.2 & 0.85 & 0.33 \\
\hline SK & 0.082 & 0.971 & -1.308 & 0.193 & 0.646 & -0.597 & 0.332 & 1.037 & -0.792 \\
\hline
\end{tabular}

This table presents the summary statistics of Winners (W), Losers (L) and MOM (momentum) portfolios across different sub samples. Panel A shows the summary statistics for traditional momentum strategies while Panel $\mathrm{B}$ and $\mathrm{C}$ show the summary statistics for volatility and variance scaled momentum strategies. AvG denotes the annualized average returns; SD is the annualized standard Deviation; SR is the annualized Sharpe ratio and SK presents the skewness of the particular portfolio.

\subsection{Risk adjusted performance}

The results in the previous two sub-sections are not adjusted for systematic risk factors. To get a concrete picture of the performance of both traditional and scaled momentum strategies, different versions of asset pricing models are tested for each momentum strategy. We present the risk-adjusted performance of each momentum strategy in table 4 for the full sample starting from September 1994 until December 2016 while in table 5, we report the performance of sub-samples. The results are consistent with analysis in the previous sections.

As expected, scaled momentum strategies performed well compared to traditional momentum strategy across all asset-pricing models. For example, using CAPM model, Constant Volatility momentum strategy has a positive annualized alpha of $12.0 \%$ (t-stats $=2.06)$ and Variance scaled Momentum strategy 
has a positive annualized alpha of $13.2 \%$ (t-stats=2.18). On the other hand, traditional momentum strategy has a positive annualized alpha of $8.4 \%$ (t-stats $=1.43)$. Using FF3 model also produces economically large and significant alphas for scaled momentum strategies, which range from $19.2 \%$ (t-stats $=3.17$ ) to $20.4 \%$ (t-stats $=3.53$ ) compared to $16.8 \%$ (t-stats $=3.18$ ) alpha of traditional momentum strategy. The alphas are even higher as compared to CAPM. This is because momentum returns are hedged against size and value factors. Moving to Carhart Four Factor Model, the alpha for the traditional momentum strategy turns negative $(-2.4 \% \mathrm{pa})$ while for scaled momentum strategies the alphas are positive but quite small (2.4\% and $4.8 \% \mathrm{pa})$ and further they are insignificant as well. To sum up, the results for the full sample reveal that irrespective of the model being used, scaled momentum strategies outperform traditional momentum strategy in terms of risk-adjusted returns.

To show that the results are not merely confined to the full sample, we divide the full sample into five sub-samples based on previous studies. Again, the results are consistent regardless of the sample or asset pricing model being used. In the first sub sample from 1994-1999, all the momentum strategies perform poorly in terms of risk-adjusted returns. However, in all three risk based models, scaled strategies have relatively higher alpha. In the 2004-2014 sub sample, when the momentum profitability is the highest, scaled strategies again perform well having higher risk adjusted returns in all asset pricing models. This shows that scaled strategies not only outperform traditional momentum strategy in the down market phase but these are also workable in up market states.

Table 4: Risk adjusted returns

\begin{tabular}{cccc|ccc}
\hline & Alphas & \multicolumn{4}{c}{ R-Square } \\
& CAPM & FF3 & CF4 & CAPM & FF3 & CF4 \\
\hline MOM & 0.007 & 0.014 & -0.002 & \multirow{2}{*}{0.028} & 0.202 & 0.867 \\
& $(1.43)$ & $(3.18)$ & $(-1.10)$ & & & \\
MOMCV & 0.01 & 0.017 & 0.002 & 0.006 & 0.128 & 0.691 \\
& $(2.06)$ & $(3.53)$ & $(0.52)$ & & & \\
MOMVS & 0.011 & 0.016 & 0.004 & 0.001 & 0.064 & 0.408 \\
& $(2.18)$ & $(3.17)$ & $(0.92)$ & & & \\
\hline
\end{tabular}

This table reports the risk adjusted return and $\mathrm{R}$-Square of traditional and scaled momentum strategies using three different version of asset pricing models. These three models are Capital Asset Pricing Model (CAPM), Fama French Three Factor Model (FF3) and Carhart Four Factor (CF4) Model. The equations for each asset pricing models. T-statistics are reported in parenthesis. For brevity, we only report the model alphas. We run monthly regression from September, 1994 to December, 2016. All alphas are reported on monthly basis.

\subsection{Performance in the long run}

In table 6 , the results of all momentum strategies are presented to assess the behavior of these strategies in the long-term. Results show that both of the scaled strategies perform better than traditional momentum strategy. The aver- 
Table 5: Risk adjusted returns sub samples

\begin{tabular}{|c|c|c|c|c|c|c|}
\hline & \multicolumn{3}{|c|}{ Alphas } & \multicolumn{3}{|c|}{ R-Square } \\
\hline & CAPM & FF3 & CF4 & CAPM & FF3 & CF4 \\
\hline \multicolumn{7}{|c|}{ 1994-1999 } \\
\hline $\mathrm{MOM}$ & $\begin{array}{l}-0.013 \\
(-1.13)\end{array}$ & $\begin{array}{l}-0.001 \\
(-0.06)\end{array}$ & $\begin{array}{l}-0.001 \\
(-0.11)\end{array}$ & 0.131 & 0.341 & 0.868 \\
\hline MOMCV & $\begin{array}{l}-0.007 \\
(-0.83)\end{array}$ & $\begin{array}{l}0.002 \\
(0.25)\end{array}$ & $\begin{array}{l}0.002 \\
(0.56)\end{array}$ & 0.101 & 0.351 & 0.86 \\
\hline MOMVS & $\begin{array}{l}-0.003 \\
(-0.52) \\
\end{array}$ & $\begin{array}{r}0.003 \\
(0.55) \\
\end{array}$ & $\begin{array}{r}0.003 \\
(0.98) \\
\end{array}$ & 0.067 & 0.332 & 0.788 \\
\hline \multicolumn{7}{|c|}{ 2001-2015 } \\
\hline MOM & $\begin{array}{l}0.011 \\
(2.12)\end{array}$ & $\begin{array}{l}0.017 \\
(3.21)\end{array}$ & $\begin{array}{l}-0.003 \\
(-1.40)\end{array}$ & 0.01 & 0.149 & 0.874 \\
\hline MOMCV & $\begin{array}{l}0.014 \\
(2.41)\end{array}$ & $\begin{array}{l}0.019 \\
(3.26)\end{array}$ & $\begin{array}{c}0.00 \\
(0.01)\end{array}$ & 0.00 & 0.079 & 0.662 \\
\hline MOMVS & $\begin{array}{c}0.014 \\
(2.26)\end{array}$ & $\begin{array}{l}0.019 \\
(2.97)\end{array}$ & $\begin{array}{l}0.003 \\
(0.55)\end{array}$ & 0.00 & 0.042 & 0.409 \\
\hline \multicolumn{7}{|c|}{ 2004-2015 } \\
\hline MOM & $\begin{array}{c}0.012 \\
(2.09)\end{array}$ & $\begin{array}{l}0.017 \\
(3.00)\end{array}$ & $\begin{array}{l}-0.001 \\
(-0.63)\end{array}$ & 0.012 & 0.178 & 0.894 \\
\hline MOMCV & $\begin{array}{l}0.017 \\
(2.48)\end{array}$ & $\begin{array}{l}0.022 \\
(3.23)\end{array}$ & $\begin{array}{l}0.003 \\
(0.70)\end{array}$ & 0.008 & 0.105 & 0.69 \\
\hline MOMVS & $\begin{array}{l}0.018 \\
(2.34) \\
\end{array}$ & $\begin{array}{l}0.024 \\
(3.01) \\
\end{array}$ & $\begin{array}{l}0.007 \\
(1.01) \\
\end{array}$ & 0.007 & 0.06 & 0.437 \\
\hline \multicolumn{7}{|c|}{$2000-2007$} \\
\hline $\mathrm{MOM}$ & $\begin{array}{l}0.007 \\
(1.43)\end{array}$ & $\begin{array}{l}0.014 \\
(3.18)\end{array}$ & $\begin{array}{l}-0.003 \\
(-1.10)\end{array}$ & 0.028 & 0.202 & 0.867 \\
\hline MOMCV & $\begin{array}{c}0.01 \\
(2.06)\end{array}$ & $\begin{array}{l}0.017 \\
(3.53)\end{array}$ & $\begin{array}{l}0.001 \\
(0.52)\end{array}$ & 0.006 & 0.128 & 0.691 \\
\hline MOMVS & $\begin{array}{c}0.011 \\
(2.18) \\
\end{array}$ & $\begin{array}{l}0.016 \\
(3.17) \\
\end{array}$ & $\begin{array}{l}0.004 \\
(0.92) \\
\end{array}$ & 0.001 & 0.064 & 0.408 \\
\hline \multicolumn{7}{|c|}{ 2009-2015 } \\
\hline MOM & $\begin{array}{c}0.013 \\
(1.60)\end{array}$ & $\begin{array}{l}0.015 \\
(2.11)\end{array}$ & $\begin{array}{l}0.001 \\
(0.45)\end{array}$ & 0.086 & 0.291 & 0.928 \\
\hline MOMCV & $\begin{array}{c}0.016 \\
(1.73)\end{array}$ & $\begin{array}{c}0.0187 \\
(2.11)\end{array}$ & $\begin{array}{l}0.004 \\
(0.75)\end{array}$ & 0.058 & 0.171 & 0.688 \\
\hline MOMVS & $\begin{array}{c}0.016 \\
(1.46)\end{array}$ & $\begin{array}{c}0.019 \\
(1.77)\end{array}$ & $\begin{array}{l}0.006 \\
(0.65)\end{array}$ & 0.035 & 0.092 & 0.413 \\
\hline
\end{tabular}

This table reports the risk adjusted return and R-Square of traditional and scaled momentum strategies using three different version of asset pricing models. These three models are Capital Asset Pricing Model (CAPM), Fama French Three Factor Model (FF3) and Carhart Four Factor (CF4) Model. The equations for each asset pricing models are given in section: (??). T-statistics are reported in parenthesis. For brevity, we only report the model alphas. We run monthly regression for different sub-samples. All alphas are reported on monthly basis.

age holding period returns (22 years of holding period) are lowest for traditional momentum strategy (2.371). Variance scaled strategy performed well among all three strategies having an average holding period return of up to 13.510. For volatility scaled strategy, holding period return is 9.646 , which is quite higher 


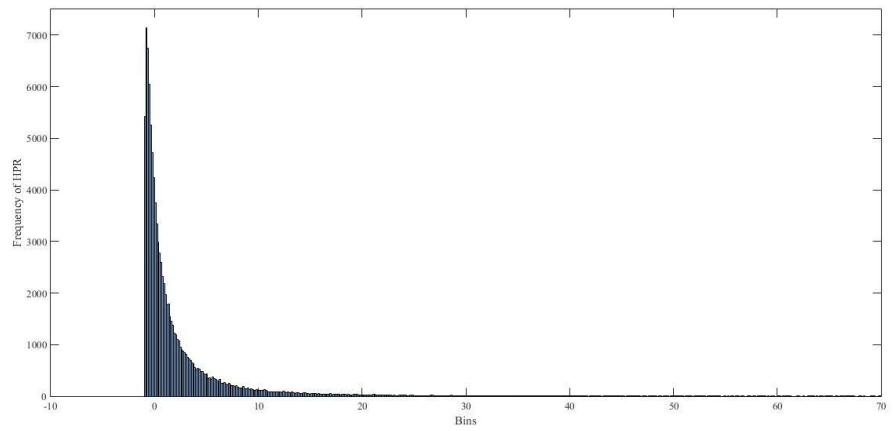

Fig. 5: Frequency distribution of traditional MOM

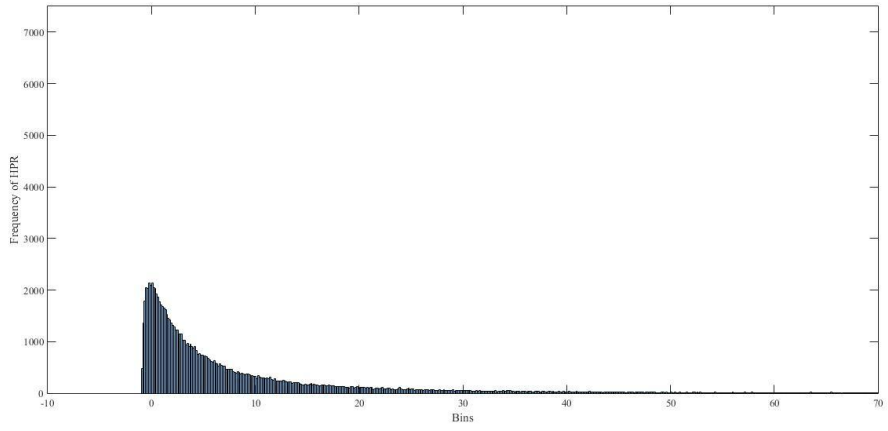

Fig. 6: Frequency distribution of constant volatility momentum

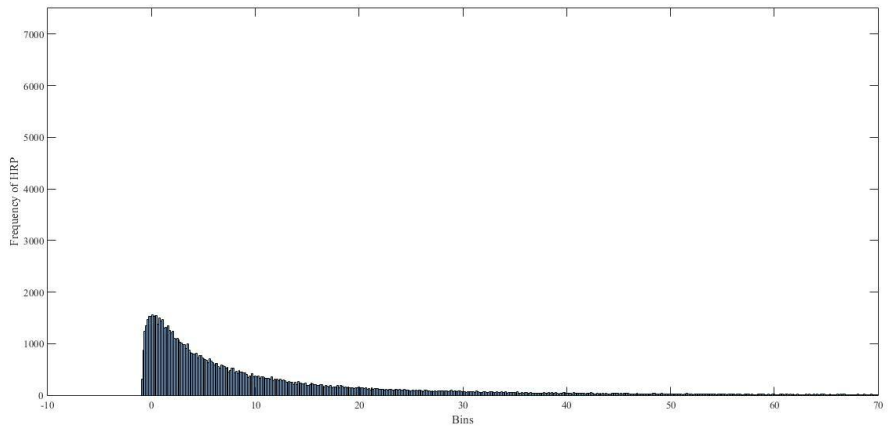

Fig. 7: Frequency distribution of variance scaled momentum

than traditional momentum strategy. In addition to this, the maximum holding period returns are also three times higher for scaled strategies compared to traditional momentum strategy. The minimum negative returns are almost identical for all three strategies. However, the probability of occurrence of negative returns is four times less for scaled strategies in comparison to traditional momentum strategies. The likelihood of getting negative returns is about $39.50 \%$ for traditional momentum strategies, whereas the probability of achieving neg-

Business Review: (2017) 12(1):1-19 
ative returns ranges from $8.27 \%$ to $11.87 \%$ for scaled strategies. This however does not mitigate the total risk of ending up with negative returns even after holding on to the investment for 22 years. We also present frequency distribution graphs in figure 5,6 and 7 to demonstrate the performance of momentum strategies. It is clear that scaled strategies have fatter tails than traditional momentum strategy which means that the probability of getting large positive returns are higher for scaled strategies than traditional momentum strategy.

Table 6: Long-term performance

\begin{tabular}{lrrr}
\hline & MOM & MOMCV & MOMVS \\
\hline AvG HPR & 2.371 & 9.646 & 13.51 \\
Max HPR & 341.569 & 926.013 & 1401.918 \\
Min HPR & -0.997 & -0.993 & -0.988 \\
Prob. Neg HPR & 39.5 & 11.87 & 8.267 \\
\hline No. Simulations & 100000 & & \\
\hline This table displays the results for the long-term perfor- \\
mance for traditional and scaled momentum strategies. We \\
run 100,000 simulations using bootstrapping in order to \\
compare the performance of different momentum strate- \\
gies. AvG HRP are the average holding period returns. \\
Max HPR are the highest holding period returns, Min HRP \\
are the minimum holding period returns. Prob. Neg HPR \\
are the probability of occurrence of negative period re- \\
turns.
\end{tabular}

\section{Conclusion}

Momentum is a pervasive and sizable anomaly around the global financial markets. Studies for the PSX show that momentum returns are not that high. Rs. 1 investment in momentum strategy increases to only Rs. 1.46 by the end of 22 years. We analyzed if this dismal performance of momentum strategy can be improved by volatility timing as is suggested in Barroso and Santa-Clara (2015); Daniel and Moskowitz (2016) for the US market. The volatility timing requires significant negative relationship between returns and lagged volatility of momentum strategy. Once this relationship withstood for momentum strategy for the PSX, we scaled the simple momentum return by the inverse of its previous volatility/variance.

We find that scaling improves the performance of momentum strategies in terms of higher risk adjusted returns and Sharpe ratios. Moreover, these results are robust across all sub samples. In all sub samples traditional momentum strategy under-performed compared to scaled momentum strategies. In addition to this, we study the performance of these momentum strategies in the long-term by simulating the distribution of holding period returns for 22 years for each strategy 100,000 times using the bootstrapping method. We find that the probability of losses is reduced more than four times (from 39\% to $8 \%$ ) in case of scaled momentum strategies therefore it can be concluded that scaled 
momentum strategies are less risky compared to traditional momentum strategies.

\section{References}

Asness CS, Moskowitz TJ, Pedersen LH (2013) Value and momentum everywhere. The Journal of Finance 68(3):929-985

Barroso P, Santa-Clara P (2015) Momentum has its moments. Journal of Financial Economics 116(1):111-120

Carhart MM (1997) On persistence in mutual fund performance. The Journal of Finance $52(1): 57-82$

Chui AC, Titman S, Wei KJ (2010) Individualism and momentum around the world. The Journal of Finance 65(1):361-392

Daniel K, Moskowitz TJ (2016) Momentum crashes. Journal of Financial Economics $122(2): 221-247$

Fama EF, French KR (1993) Common risk factors in the returns on stocks and bonds. Journal of Financial Economics 33(1):3-56

Griffin JM, Kelly PJ, Nardari F (2010) Do market efficiency measures yield correct inferences? a comparison of developed and emerging markets. The Review of Financial Studies $23(8): 3225-3277$

Grundy BD, Martin JSM (2001) Understanding the nature of the risks and the source of the rewards to momentum investing. The Review of Financial Studies 14(1):29-78

Habib-Ur-Rahman, Mohsin HM (2012) Momentum effect: empirical evidence from karachi stock exchange. The Pakistan Development Review pp 449-461

Ince OS, Porter RB (2006) Individual equity return data from thomson datastream: Handle with care! Journal of Financial Research 29(4):463-479

Jegadeesh N, Titman S (1993) Returns to buying winners and selling losers: Implications for stock market efficiency. The Journal of finance 48(1):65-91

Jensen MC (1968) The performance of mutual funds in the period 1945-1964. The Journal of finance $23(2): 389-416$

Khan S, et al (2016) Momentum strategies and karachi stock exchange. Pakistan Journal of Statistics and Operation Research

Kusnadi Y, Hameed A (2002) Momentum strategies: Evidence from pacific basin stock market. Journal of Financial Research 25(3):383

Moreira A, Muir T (2016) Volatility-managed portfolios. The Journal of Finance

Reuters T (2013) Worldscope database datatype definitions guide

Rouwenhorst KG (1999) Local return factors and turnover in emerging stock markets. The journal of finance 54(4):1439-1464

Schmidt PS, Von Arx U, Schrimpf A, Wagner AF, Ziegler A (2016) On the construction of common size, value and momentum factors in international stock markets: A guide with applications

Shah SHA, Shah A (2015) Can momentum portfolios earn more in the karachi stock exchange? Pakistan Business Review 17(1):80-98

Sharpe WF (1964) Capital asset prices: A theory of market equilibrium under conditions of risk. The Journal of Finance 19(3):425-442

Tauseef SF, Nishat M (2016) Can investors benefit from momentum trading? evidence from an emerging market

Business Review: (2017) 12(1):1-19 